\title{
O processo de aquisiçao de linguagem para a criança com transtorno do espectro
}

\section{autista: artigo de revisão}

\author{
The language acquisition process for children with autistic spectrum disorder: review article \\ El proceso de adquisición del lenguaje para niños con trastorno del espectro autista: artículo de \\ revisión
}

Recebido: 29/12/2020 | Revisado: 30/12/2020 | Aceito: 04/01/2021 | Publicado: 04/01/2021

\author{
Wanderson Mineiro da Silva \\ ORCID: https://orcid.org/0000-0001-6795-6443 \\ Faculdade de Ensino Superior do Piauí, Brasil \\ E-mail:wandersonmineiro_1@hotmail.com \\ Aracy Tereza Castelo Branco Coelho \\ ORCID: https://orcid.org/0000-0002-5277-1582 \\ Faculdade de Ensino Superior do Piauí, Brasil \\ E-mail: aracycoelho@yahoo.com.br
}

\begin{abstract}
Resumo
Objetivo: Apresentar levantamento de publicações cientificas sobre a aquisição da linguagem de crianças do transtorno do espectro autista, abordando as intervenções utilizados pelos fonoaudiólogos. Método: Esta pesquisa é uma revisão de literatura crítica, de análise qualitativa, que tem o intuito de sistematizar resultados de artigos, teses e resultados de pesquisas realizadas com o processo de aquisição de linguagem em indivíduos com transtorno do Espectro Autista e o fonoaudiólogo como profissional relevante neste processo. Resultados: Observou-se que os estudos encontrados completam vários aspectos no processo de aquisição da linguagem, estratégias e práticas que favorecem esse processo, escola e profissionais com intervenções com base na singularidade de cada sujeito, favorecendo a inserção social dos autistas em meios comunicativos e conversacionais. Conclusão: Os artigos e teses apresentadas contribuem para apresentar pontuações relevantes sobre o processo de aquisição da linguagem em autista.
\end{abstract}

Palavras-chave: Linguagem; TEA; Fonoaudiologia.

\begin{abstract}
Objective: To present a survey of scientific publications on the language acquisition of children with autism spectrum disorder, addressing the interventions used by speech therapists. Method: This research is a review of critical literature, of qualitative analysis, which aims to systematize results of articles, theses and results of research carried out with the process of language acquisition in individuals with Autism Spectrum Disorder and the speech therapist as a professional relevant in this process. Results: It was observed that the studies found complete several aspects in the process of language acquisition, strategies and practices that favor this process, school and professionals with interventions based on the uniqueness of each subject, favoring the social insertion of autistic people in communicative and conversational. Conclusion: The articles and theses presented contribute to present relevant scores on the language acquisition process in autistic people.
\end{abstract}

Keywords: Language; TEA; Speech therapy.

\section{Resumen}

Objetivo: Presentar una encuesta de publicaciones científicas sobre la adquisición del lenguaje de niños con trastorno del espectro autista, abordando las intervenciones utilizadas por los logopedas. Método: Esta investigación es una revisión de la literatura crítica, de análisis cualitativo, que tiene como objetivo sistematizar los resultados de artículos, tesis y resultados de investigaciones realizadas con el proceso de adquisición del lenguaje en personas con Trastorno del Espectro Autista y el logopeda como profesional. relevante en este proceso. Resultados: Se observó que los estudios encontraron varios aspectos completos en el proceso de adquisición del lenguaje, estrategias y prácticas que favorecen este proceso, la escuela y los profesionales con intervenciones basadas en la singularidad de cada sujeto, favoreciendo la inserción social de las personas autistas en el ámbito comunicativo y comunicativo. conversacional. Conclusión: Los artículos y tesis presentados contribuyen a presentar puntuaciones relevantes sobre el proceso de adquisición del lenguaje en personas autistas.

Palabras clave: Idioma; TEA; Terapia del lenguaje. 


\section{Introdução}

Paiva Júnior (2020) define o transtorno do espectro do autismo TEA como uma condição de saúde que tem como características dificuldades na comunicação social e comportamento, pontos como a socialização, comunicação verbal e nãoverbal, interesses restritivos e movimentos repetitivos, podendo abranger vários níveis de comprometimento.

Nas considerações de Ferraro (2016) vale salientar que uma criança que possui o autismo pode apresentar maior ou menor grau de desordem na linguagem, além de como citado anteriormente, ser uma criança verbal ou não verbal, isso vai depender da Patologia e da gravidade associada ao autismo.

A presente pesquisa objetiva compreender a aquisição da linguagem em crianças com Transtorno do espectro autista. Segundo Leite, Bittencourt e Silva (2015) considerando ser um processo natural do desenvolvimento humano, a aquisição da linguagem oral, se difere do processo de aprendizagem, pois leitura e escrita são adquiridos por meio da aprendizagem, geralmente realizada na escola.

Neste viés, Ferraro (2016) acrescenta que pontos evidentes do autismo estão relacionados a linguagem, a presença ou ausência da fala caracteriza o desenvolvimento atípico da linguagem e das manifestações verbais. As questões linguísticas, levando em consideração as habilidades pragmáticas têm papel relevante para as crianças dentro do Transtorno do Espectro autista TEA. Segundo o Instituto Neurosaber (2017) no processo de aprendizagem o fonoaudiólogo tem papel importante, atua junto a uma equipe multiprofissional, além de suas demandas, possuindo várias responsabilidades, junto a outros profissionais, suas ações também estão ligadas ao planejamento escolar.

Atuação fonoaudiológica é importante na promoção da linguagem, as práticas exercidas por esses profissionais são relevantes neste processo. Na aprendizagem, é considerável que a criança no processo de aquisição de linguagem receba estímulos, para Bigochinski e Eckstein (2016) as estimulações das habilidades são consideradas essenciais à aquisição da linguagem escrita, pois são atividades complexas e necessitam de um leque de aptidões. Para o autista estes estímulos são necessários e devem ser realizados por profissionais qualificados.

Desta forma, o profissional de fonoaudiologia contribui para que o aluno com TEA alcance um bom desempenho e desenvolvimento e receba as intervenções necessárias para uma aquisição de linguagem. Considerando as informações acima a problemática que se apresenta como ocorre a aquisição da linguagem no Transtorno do espectro Autista?

Assim, o objetivo desta pesquisa é apresentar um levantamento de publicações cientificas sobre a aquisição da linguagem em crianças do transtorno do espectro autista, abordando a importância do fonoaudiólogo. E, como objetivos específicos compreender quais as intervenções utilizadas pelo fonoaudiólogo para o desenvolvimento da aquisição de linguagem do autista; descrever dificuldades de interação; apresentar considerações relevantes sobre a consciência fonologica e sua relação com autismo.

É importante ressaltar que essa pesquisa assume uma grande relevância tanto para o profissional de fonoaudiologia, como para toda a sociedade, pois discorre sobre a fonoaudiologia, linguagem e autismo como uma base de desenvolvimento social e educacional para os autistas, sendo que precisa ser estudada e utilizada ainda como uma fonte de pesquisa para eventuais estudos futuros.

\section{Contextualizando os Aportes Teóricos sobre Autismo}

Nas pontuações de Teixeira (2016) o Transtorno do Espectro Autista (TEA) conhecido também como autismo é um distúrbio neurológico, presente desde o nascimento ou no início da infância e se caracteriza por comprometer a interação social, comunicação verbal e não verbal com episódios frequentes de comportamentos restritivos e repetitivos e com dificuldade de coordenação motora. 
As características observadas na síndrome do autismo variam na forma de exteriorização dos desvios de relações interpessoais, linguagem, motricidade, percepção e patologias associadas ao distúrbio. A intensidade destes desvios, os estados mais determinantes, também é diversificada (Rodrigues; Spencer, 2015, p. 21).

Assumpção Jr e Kuczynski (2018) reforçam afirmando que o Tea é considerado um transtorno do desenvolvimento que possui diferentes níveis, atinge as áreas de interação social, comunicação e comportamento, apresentando sintomas em frequência gradual e dificuldades motoras.

Ainda, conforme os pesquisadores supracitados, os mesmos apresentam um quadro de classificação do DSM (V), em que os níveis de gravidade do TEA são avaliados e os déficits na comunicação e comportamento social, servem como base nos sintomas contextuais e ambientais, considerando que os atrasos na linguagem, não são podem ser considerados como características particulares do TEA e sim como fator de influência nos sintomas clínicos.

É relevante pontuar que grande parte dos profissionais e pais utilizam, condições para diagnosticar tipos de autismo, porém essa definição não é mais oficial, os termos utilizados como: autismo clássico, autismo atípico, Síndrome de Asperger ou outras denominações, foram substituídos, a classificação conforme o DSM V (2013) que se apresenta em três níveis: leve, moderado e severo, passando assim a ser caracterizado o transtorno do espectro autista. Abaixo será apresentado um quadro com os níveis de gravidade do TEA.

Quadro 1 - Níveis de gravidade dos tea dsm v (2013).

\begin{tabular}{|c|c|c|}
\hline Gravidade do TEA & Comunicação Social & $\begin{array}{l}\text { Comportamentos repetitivos e interesses } \\
\text { restritos }\end{array}$ \\
\hline $\begin{array}{l}\text { Nível } 3 \text { - Requer } \\
\text { suporte intenso }\end{array}$ & $\begin{array}{l}\text { Graves déficits em comunicação verbal } \\
\text { e não verbal ocasionando graves } \\
\text { prejuízos no funcionamento social; } \\
\text { interações sociais muito limitadas e } \\
\text { mínima resposta social ao contato com } \\
\text { outras pessoas. }\end{array}$ & $\begin{array}{l}\text { Preocupações, rituais imutáveis e } \\
\text { comportamentos repetitivos que interferem muito } \\
\text { com o funcionamento em todas as esferas. } \\
\text { Intenso desconforto quando rituais ou rotinas são } \\
\text { interrompidas, com grande dificuldade no } \\
\text { redirecionamento dos interesses ou de se dirigir } \\
\text { para outros rapidamente. }\end{array}$ \\
\hline $\begin{array}{l}\text { Nível } 2 \text { - Requer } \\
\text { suporte grande }\end{array}$ & $\begin{array}{l}\text { Graves déficits em comunicação social } \\
\text { verbal e não verbal que aparecem } \\
\text { sempre, mesmo com suportes, em } \\
\text { locais limitados. Observam-se } \\
\text { respostas reduzidas ou anormais ao } \\
\text { contato social com outras pessoas. }\end{array}$ & $\begin{array}{l}\text { Preocupações ou interesses fixos frequentes, } \\
\text { óbvios a um observador casual, e que interferem } \\
\text { em vários contextos. Desconforto e frustração } \\
\text { visíveis quando rotinas são interrompidas, o que } \\
\text { dificulta o redirecionamento dos interesses } \\
\text { restritos. }\end{array}$ \\
\hline $\begin{array}{l}\text { Nível } 1 \text { - Requer } \\
\text { suporte }\end{array}$ & $\begin{array}{l}\text { Sem suporte local o déficit social } \\
\text { ocasiona prejuízos. Dificuldades em } \\
\text { iniciar relações sociais e claros } \\
\text { exemplos de respostas atípicas e sem } \\
\text { sucesso no relacionamento social. } \\
\text { Observa-se interesse diminuído pelas } \\
\text { relações sociais. }\end{array}$ & $\begin{array}{l}\text { Rituais e comportamentos repetitivos interferem, } \\
\text { significativamente, no funcionamento em vários } \\
\text { contextos. Resiste às tentativas de interrupção } \\
\text { dos rituais e ao redirecionamento de seus } \\
\text { interesses fixos. }\end{array}$ \\
\hline
\end{tabular}

Fonte: Assumpção Jr e Kuczynski (2018, p. 26). 
Considerando o exposto, Sampaio e Oliveira (2017) afirma que no autismo existem dificuldades na comunicação e interação social, com isso a utilização da fala pode ser afetada, quando o autista apresenta essa dificuldade, comprometendo o seu aprendizado da leitura, considerando que é importante ter o domínio da fala para aprender a ler.

Autista que se enquadram no nível 1, na maioria dos casos apresentam um nível de linguagem oral amplo e satisfatório em âmbito educacional, entretanto existe uma quantidade considerável de autistas que apresenta resultados insatisfatórios no processo de aprendizagem da leitura e escrita, por não cumprirem o apoio de pré-requisitos necessários ao processo de ensino aprendizagem. Assim a próxima seção será apresentada aquisição da consciência fonológica dentro do Transtorno do espectro autista (TEA).

\section{Considerações Relevantes sobre Consciência Fonológica e o Transtorno do Espectro Autista (tea)}

Nas considerações de Sampaio e Oliveira (2017) a aprendizagem holística da leitura e da escrita, exige do aprendiz o cumprimento de especificações, no qual, nortearão o processo do desenvolvimento. "As habilidades da leitura e da escrita, por serem habilidades complexas, exigem da criança muitos pré-requisitos (Oliveira; Sampaio, 2017, p. 16). Essas informações mostram a amplitude do conhecimento e do processo de ensino-aprendizagem.

Segundo Donicht, Ceron e Keske-Soares (2017) a linguagem oral é composta pela fonologia, as alterações que surgem são denominadas desvios fonológicos, um distúrbio que apresenta como característica na fala da criança, omissões e substituições de fonemas em idades em que não deveria mais ocorrer, podendo também surgir alterações na consciência fonológica.

A consciência fonológica também conhecida como habilidade metalinguística é a capacidade da manipulação, percepção do som e das palavras, definida ainda como a clareza sonora do som, ou seja, a discriminação e a nomeação das letras (Freire, 2018). Neste viés Rosal et al. (2015, p. 2) afirmam:

A importância da consciência fonológica para aprendizagem da língua escrita, já que para a criança aprender a ler e escrever no sistema de escrita alfabético é necessário a percepção da relação grafema-fonema. Para isso, são fundamentais as habilidades em identificação, análise, síntese e manipulação dos componentes fonológicos em níveis silábico e fonêmico, que compõem a consciência fonológica

Assim, quando identificada alguma alteração na capacidade fonológica é necessária a intervenção. Segundo o Manual de Orientação do TEA (2019) as intervenções são realizadas pela equipe multidisciplinar, ou seja, familiares, equipe de saúde; fonoaudiólogos, psicólogos, terapeutas comportamentais, psicopedagogo, assistentes socais, fisioterapeutas e educadores físicos que tem o objetivo de contribuir nas modificações de comportamento e no aprendizado, das crianças com TEA.

Conforme Assumpção Jr e Kuczynski (2018) o autista leve, geralmente apresenta uma excelente linguagem oral, o que favorece sua comunicação, porém suas habilidades motoras, ainda precisam de um desenvolvimento aliado ao seu pensamento, sendo fator colaborativo para um engajamento comunicativo e eficiente, diferenciando-se assim aos demais níveis dentro do autismo, que em quesito de linguagem, apresenta maior complexidade, desfavorecendo o aprendizado e comunicação para convivo social e afetivo.

Segundo Ishihara, Tamanaha e Perissinoto (2015), é importante que profissionais que detectem as dificuldades dos autistas, reduzir déficits educacionais, sendo o auxílio da comunidade pedagógica e o apoio da fonoaudiologia educacional, ações importantes para evitar prejuízos pragmáticos. 
Com base nisso, segundo Firmino (2017) o fonoaudiólogo contribuirá satisfatoriamente no processo aquisitivo da linguagem e maturação total do desenvolvimento cognitivo e motor, propiciando assim amplamente a caracterização de atividades que favoreçam seu desenvolvimento e participação junto à sociedade

Para Nunes e Walter (2016) as alterações marcantes no desenvolvimento autista são ao nível da pragmática, da semântica e da sintaxe. Verifica-se dificuldade na manutenção do diálogo, sendo as tarefas de iniciação de conversa (de interesse para todos os interlocutores) prejuízos da linguagem, extremamente difíceis para execução.

Dos profissionais que auxiliam autista para Pastorello (2018) o fonoaudiólogo em suas intervenções visa a melhoria dos sintomas relacionado a linguagem e comunicação, seja ela verbal ou não - verbal. Assim realizando uma intervenção precoce e continua o autista pode ser capacitado para evolução e desenvolvimento conforme um programa terapêutico especifico.

Conforme a Resolução n 309 de 2005 do Conselho Federal de Fonoaudiologia deve existir uma parceria entre os fonoaudiólogos e docentes visando otimizar o processo de ensino - aprendizagem, por meio de ações que favorecem a promoção, aprimoramento e prevenção de alterações da voz, audição, linguagem, motricidade oral.

Para Freire (2018) o fonoaudiólogo vai direcionar sua atuação, capacitando, assessorando e realizando palestras e orientações, nas escolas, fortalecendo e promovendo a saúde e educação, haja vista que esse profissional, pode identificar transtornos de aprendizagem.

$\mathrm{Na}$ consciência fonológica ocorre variações da linguagem, apresentando-se algumas peculiaridades que são importantes para que possamos compreender os comportamentos dos pequenos, seja na sua comunicação, ou transmissão de informações. Essas habilidades se desenvolvem primeiramente pelo contato com a linguagem oral e, posteriormente, com a aquisição da escrita (Freire, 2018 p.28).

\section{Metodologia}

Neste trabalho foi desenvolvida uma pesquisa bibliográfica utilizando diversos mecanismos como os bancos da A Scientific Electronic Library Online -SCIELO, O Google Scholar - Google Acadêmico, e Literatura Latino-americana e do Caribe em Ciências da Saúde - Lilacs, Sistema Online de Busca e Análise de Literatura médica - Medline, entre os anos de 2015 a 2020 em língua Portuguesa, Inglesa e espanhol em busca de publicações relevantes que discutissem o assunto a ser de fundamental interesse que é, autismo, fonoaudiologia, consciência fonológica, linguagem, assim como livros, teses de mestrado e doutorado, que discutem tal temática.

Como propósito geral a pesquisa é de caracter exploratória, "seu planejamento tende a ser bastante flexível, pois interessa considerar os mais variados aspectos relativos ao fato ou fenômeno estudado" (Gil, 2017, p.33). Quando a natureza dos dados é uma pesquisa qualitativa.

Utiliza o método dedutivo, dados com informações teóricas já existentes no texto e opinião de autores. O método indutivo segundo Cervo, Bervian e Silva (2014, p.44) "baseia-se na generalização de propriedades comuns e certos números de casos até agora observados e a todos fatos similares que podem ser verificados no futuro".

Como critérios de inclusão foram catalogados os artigos que agregam aos seus objetivos, a descrição de proposta apresenta estratégias de intervenção fonoaudiologica, visando a aquisição de linguagem de crianças na fase da pré-escolar com TEA. E de exclusão os artigos que não agregaram aos seus objetivos, a descrição da aquisição de linguagem, consciência fonológica, autismo, assim como aqueles publicados antes de 2015. 
Foram retirados os artigos que não estavam conforme as condicionalidades propostas para este levantamento, onde foi possível relatar que nos artigos encontrados os descritores, autismo, aquisição de linguagem, consciência fonológica, que serviram como direcionamento.

Neste viés, após analisados os artigos e teses encontradas foi construído um quadro com 09 estudos relevantes sobre o assunto. Conforme observado na tabela 1, a eficácia da intervenção fonoaudiologica na aquisição de linguagem em crianças com o Transtorno do espectro Autista.

Após a leitura dos artigos, com base nas categorias temáticas as informações foram retiradas e fichadas para posterior elaboração de quadro dividido por colunas com o intuito de melhor organizar o trabalho. Abaixo a tabela com os estudos que tratam da aquisição de linguagem, fonoaudiologia e Transtorno do Espectro Autista.

\section{Resultados e Discussão}

A seleção dos estudos foi realizada mediante a leitura criteriosa do título e resumo, a fim de verificar a adequação com a questão norteadora. Na sequência foram delimitadas as variáveis para análise, como: autor, ano, objetivo, resultados e conclusão do estudo com o enfoque temático para análise e discussão dos dados

O ano de 2015 e 2016 apareceram como os de maior produção com 3 artigos, nos anos de 2016 e 2018 retrataram 2 produções respectivamente sobre a problemática. No ano de 2017 e 2019 apresenta 01 publicações cada, somando 9 no total. Em relação às abordagens metodológicas utilizadas nas 10 produções científicas, sendo 3 estudos utilizaram de abordagem qualitativa, quantitativa, estudos transversais.

O Quadro 1 a seguir apresenta os resultados encontrados divididos por autor, ano da publicação, objetivos, resultados e conclusão dos artigos selecionados. Observando os artigos contidos no referido quadro é possível analisar através de amostras a contribuição do fonoaudiólogo na aquisição de linguagem do autista.

Quadro 2 - Artigos selecionados divididos por categorias apresentando considerações sobre aquisição de linguagem em indivíduos com Transtorno do Espectro Autista.

\begin{tabular}{|c|c|c|c|}
\hline AUTOR/ANO & OBJETIVOS & RESULTADOS & CONCLUSÃO \\
\hline $\begin{array}{l}\text { MONTICELLI } \\
(\mathbf{2 0 1 5})\end{array}$ & $\begin{array}{l}\text { Analisar os processos do brincar } \\
\text { e de aquisição de linguagem de } \\
\text { três crianças com autismo, a } \\
\text { partir da mediação da terapeuta, } \\
\text { em contexto lúdico. }\end{array}$ & $\begin{array}{l}\text { Os resultados } \\
\text { mostraram que, a partir } \\
\text { da mediação da } \\
\text { terapeuta, as crianças } \\
\text { passaram a atribuir } \\
\text { funções aos brinquedos } \\
\text { e a apresentar } \\
\text { desenvolvimento de } \\
\text { intenção comunicativa. } \\
\text { Durante o processo de } \\
\text { desenvolvimento do } \\
\text { brincar apresentaram } \\
\text { indícios de linguagem } \\
\text { não-verbal e verbal para } \\
\text { solicitar ou mostrar } \\
\text { brinquedos, solucionar } \\
\text { problemas ou, ainda, } \\
\text { demonstrar } \\
\text { necessidades e desejos. }\end{array}$ & $\begin{array}{lr}\text { As situações lúdicas } \\
\text { mediadas } & \text { pela } \\
\text { terapeuta } & \\
\text { possibilitaram } & \text { a } \\
\text { construção } & \text { de } \\
\text { significados neste } \\
\text { contexto, ampliando } \\
\text { as oportunidades de } \\
\text { vivências } \\
\begin{array}{ll}\text { comunicativas destas } \\
\text { crianças. }\end{array}\end{array}$ \\
\hline & $\begin{array}{l}\text { A eficácia da intervenção } \\
\text { terapêutica fonoaudiológica para } \\
\text { crianças com Distúrbios do }\end{array}$ & $\begin{array}{llr}\text { Observou-se } & & \text { maior } \\
\text { evolução do } & \text { GT no } \\
\text { Autism } & & \text { Behavior }\end{array}$ & $\begin{array}{l}\text { A tendência de melhor } \\
\text { desempenho das } \\
\text { crianças atendidas na }\end{array}$ \\
\hline
\end{tabular}




\begin{tabular}{|c|c|c|c|}
\hline $\begin{array}{l}\text { TAMANAHA; } \\
\text { CHIARI ; } \\
\text { PERISSINOTO } \\
\text { (2015) }\end{array}$ & Espectro do Autismo. & $\begin{array}{l}\text { Checklist, Avaliação } \\
\text { Interação e na Amostra } \\
\text { de comportamento } \\
\text { vocal. Tanto as mães } \\
\text { quanto a fonoaudióloga } \\
\text { perceberam mudanças } \\
\text { comportamentais. }\end{array}$ & $\begin{array}{l}\text { intervenção direta e } \\
\text { indireta mostrou que } \\
\text { esta associação foi } \\
\text { fundamental. }\end{array}$ \\
\hline $\begin{array}{c}\text { ISHIHARA, } \\
\text { TAMANAHA e } \\
\text { PERISSINOTO } \\
\text { (2015) }\end{array}$ & $\begin{array}{l}\text { Verificar e comparar o } \\
\text { desempenho de crianças e } \\
\text { adolescentes com Transtorno } \\
\text { Específico de Linguagem e Fala } \\
\text { (TEL) e Transtorno do Espectro } \\
\text { Autista (TEA) em teste formal e } \\
\text { padronizado que avalia a } \\
\text { competência de linguagem, } \\
\text { especificamente em prova de } \\
\text { ambiguidade. }\end{array}$ & $\begin{array}{lr}\text { Houve } & \text { diferença } \\
\text { significativa } & \text { com } \\
\text { melhor desempenho do } \\
\text { grupo } \quad \text { TEL } & \text { em } \\
\text { comparação ao } & \text { grupo } \\
\text { TEA. } & \end{array}$ & $\begin{array}{l}\text { Foi possível analisar e } \\
\text { comparar a } \\
\text { performance dos } \\
\text { grupos em atividade } \\
\text { metalinguística } \\
\text { verificar melhor } \\
\text { desempenho do grupo } \\
\text { Transtorno Específico } \\
\text { de Linguagem e Fala } \\
\text { em relação ao } \\
\text { Transtorno } \\
\text { Espectro Autista, na } \\
\text { interpretação } \\
\text { informações } \\
\text { ambíguas. }\end{array}$ \\
\hline $\begin{array}{l}\text { NASCIMENTO; } \\
\text { FERREIRA } \\
\text { BRAUN (2016) }\end{array}$ & $\begin{array}{l}\text { Mapear e analisar o estado da } \\
\text { arte acerca do processo de } \\
\text { escolarização desse sujeito, ao } \\
\text { longo de uma década, } \\
\text { disponível na base de dados da } \\
\text { Scientific Eletronic Library } \\
\text { Online (SciELO-Brasil). }\end{array}$ & 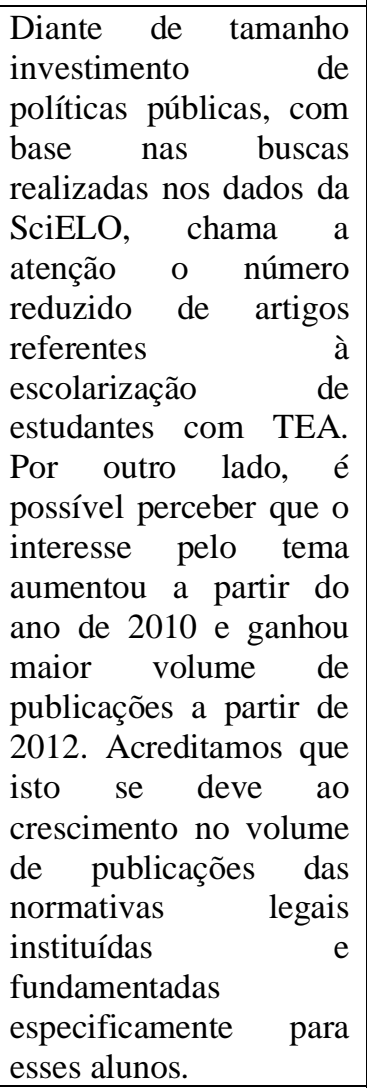 & $\begin{array}{l}\text { A partir do } \\
\text { mapeamento e das } \\
\text { análises realizadas } \\
\text { constatamos, entre } \\
\text { outros aspectos, que } \\
\text { ainda são poucos os } \\
\text { trabalhos que } \\
\text { investigam o processo } \\
\text { de escolarização e, } \\
\text { principalmente, } \\
\text { organização } \\
\text { aplicação } \\
\text { estratégias ou recursos } \\
\text { em sala de aula com o } \\
\text { este aluno. }\end{array}$ \\
\hline PEROTTI (2016) & $\begin{array}{l}\text { Sublinha questões voltadas para } \\
\text { o processo de alfabetização em } \\
\text { Língua Portuguesa Brasileira, } \\
\text { do aluno portador do TEA - } \\
\text { Transtorno do Espectro do } \\
\text { Autista -, em um recorte de } \\
\text { escolas públicas e privadas da } \\
\text { região metropolitana de Belo } \\
\text { Horizonte. }\end{array}$ & $\begin{array}{l}\text { Observa a mediação } \\
\text { entre sujeito atípico, } \\
\text { ensino sistematizado e } \\
\text { instituição escolar. } \\
\text { Revisita o papel do } \\
\text { professor alfabetizador } \\
\text { e indaga sobre as } \\
\text { mudanças e os apoios } \\
\text { que deveriam acontecer } \\
\text { na escola atual para }\end{array}$ & $\begin{array}{l}\text { Entende que, só após } \\
\text { uma investigação } \\
\text { particularizada, a } \\
\text { escola poderá oferecer } \\
\text { atividades que se } \\
\text { aproximem mais das } \\
\text { necessidades } \\
\text { circunstâncias no } \\
\text { quadro da atipia. }\end{array}$ \\
\hline
\end{tabular}




\begin{tabular}{|c|c|c|c|}
\hline & & $\begin{array}{l}\text { motivar ações insertivas } \\
\text { no/do desenvolvimento } \\
\text { linguístico do sujeito de } \\
\text { perfil autístico. }\end{array}$ & \\
\hline $\begin{array}{c}\text { PERIN; SILVA } \\
\text { OLIVEIRA (2017) }\end{array}$ & 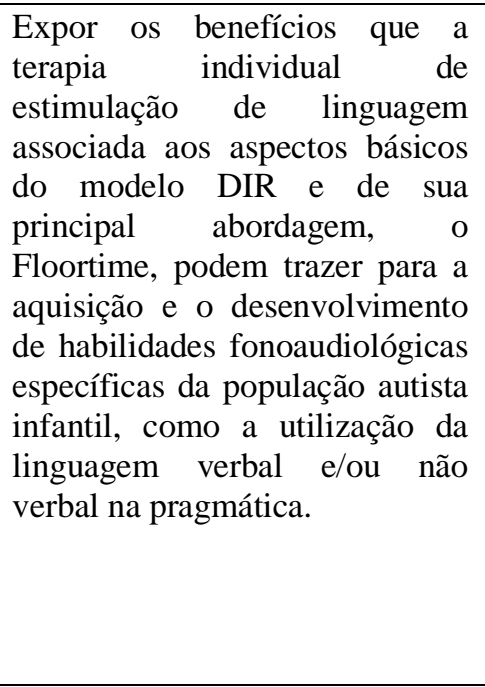 & $\begin{array}{l}\text { Diminuição } r \\
\text { percentual dos atos } \\
\text { comunicativos gestuais } \\
\text { e aumento do número } \\
\text { total de } \\
\text { comunicativos atos } \\
\text { expressos pela criança, } \\
\text { do número total de atos } \\
\text { comunicativos } \\
\text { expressos por minuto } \\
\text { pela criança, do } \\
\text { percentual do espaço } \\
\text { comunicativo ocupado } \\
\text { pela criança e do } \\
\text { percentual total dos atos } \\
\text { comunicativos verbais e } \\
\text { vocais. }\end{array}$ & $\begin{array}{l}\text { Evolução no perfil } \\
\text { pragmático ra da } \\
\text { comunicação de todos } \\
\text { os sujeitos da } \\
\text { pesquisa, uma vez que } \\
\text { as interações } \\
\text { interpessoais e sociais, } \\
\text { assim como o espaço } \\
\text { comunicativo } \\
\text { aumentaram a } \\
\text { juntamente com a } \\
\text { intenção comunicativa } \\
\text { a partir da utilização } \\
\text { da estimulação de } \\
\text { linguagem baseada no } \\
\text { modelo DIR } \\
\text { Floortime. }\end{array}$ \\
\hline $\begin{array}{l}\text { RABELO; } \\
\text { LABIGALINI } \\
(\mathbf{2 0 1 7})\end{array}$ & $\begin{array}{l}\text { Analisar a } \text { aquisição } \text { e } \\
\text { desenvolvimento da linguagem } \\
\text { através de intervenções } \\
\text { fonoaudiológicas com um } \\
\text { sujeito diagnosticado com } \\
\text { Transtorno do Espectro Autista } \\
\text { (TEA). }\end{array}$ & 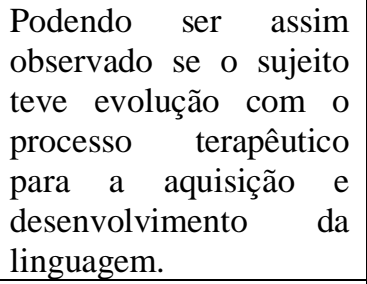 & $\begin{array}{l}\text { O empoderamento } \\
\text { seria a primeira } \\
\text { condição para que a } \\
\text { pessoa se aproprie da } \\
\text { importância ra da } \\
\text { linguagem do viver } \\
\text { em sociedade. }\end{array}$ \\
\hline $\begin{array}{l}\text { MARQUES } \\
\quad(\mathbf{2 0 1 8})\end{array}$ & $\begin{array}{l}\text { Fazer uma revisão crítica da } \\
\text { literatura afim de olhar para } \\
\text { pesquisas realizadas com a } \\
\text { intenção de fortalecer a } \\
\text { consciência } \\
\text { indivíduos fonológica } \\
\text { desenvolvimentos de } \\
\text { síndrome de Williams autro atismo } \\
\text { Síndrome de Down e dislexia } \\
\text { com possíveis impactos nas } \\
\text { habilidades de leitura e escrita }\end{array}$ & $\begin{array}{lr}\text { Com relação às crianças } \\
\text { com autismo todas Elas } \\
\text { obtiveram } & \text { avanços } \\
\text { importantes } & \text { com } \\
\text { treinamento } & \text { mostrando } \\
\text { melhores índices de } \\
\text { pontuação e leitura } \\
\text { consciência fonológica } \\
\text { comportamento verbal e } \\
\text { motivação }\end{array}$ & $\begin{array}{l}\text { As Pesquisas mostram } \\
\text { que as intervenções } \\
\text { com foco em } \\
\text { consciência } \\
\text { fonológica rão } \\
\text { favoráveis ro } \\
\text { desenvolvimento de } \\
\text { habilidades de leitura } \\
\text { e escrita também } \\
\text { nessas populações e } \\
\text { suscitam reflexões a } \\
\text { respeito das } \\
\text { metodologias } \\
\text { utilizadas tempos de } \\
\text { Treinamento número } \\
\text { de Informante entre } \\
\text { outros aspectos. }\end{array}$ \\
\hline \multirow[t]{2}{*}{$\begin{array}{l}\text { BARCELAR E } \\
\text { NASCIMENTO } \\
\quad(\mathbf{2 0 1 8})\end{array}$} & $\begin{array}{l}\text { Objetivo verificar a aquisição da } \\
\text { linguagem de crianças com } \\
\text { autismo e estabelecer uma } \\
\text { relação entre a aquisição da } \\
\text { linguagem e a dificuldade no } \\
\text { processo de interação social de } \\
\text { crianças com autismo. }\end{array}$ & $\begin{array}{l}\text { Conhecer acerca da } \\
\text { comunicação } \\
\text { estabelecida da criança } \\
\text { acometidararara pelo } \\
\text { transtorno autista es } \\
\text { demais colegas de sala } \\
\text { de aula. }\end{array}$ & $\begin{array}{l}\text { Conclui-se, então, que } \\
\text { as diversas } \\
\text { dificuldades relatadas } \\
\text { na } \\
\text { investigação, como a } \\
\text { interação social, que, } \\
\text { além de potencializada } \\
\text { pela própria etiologia } \\
\text { da doença, é bastante } \\
\text { afetada }\end{array}$ \\
\hline & 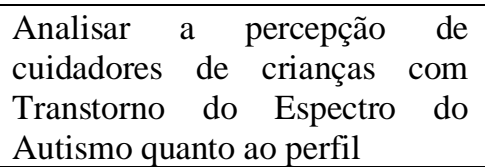 & $\begin{array}{l}\text { No PFC-C os pais } \\
\text { relataram aumento na } \\
\text { ocorrência dos meios } \\
\text { gestual, vocal e verbal }\end{array}$ & $\begin{array}{lr}\text { As orientações } & \text { de } \\
\text { comunicação } & \text { para } \\
\text { cuidadores de crianças } \\
\text { com }\end{array}$ \\
\hline
\end{tabular}




\begin{tabular}{|c|c|c|c|}
\hline $\begin{array}{l}\text { BALESTRO; } \\
\text { FERNANDES } \\
\quad(2019)\end{array}$ & $\begin{array}{l}\text { funcional da comunicação de } \\
\text { seus filhos em três momentos, } \\
\text { antes e após as orientações. }\end{array}$ & $\begin{array}{lr}\text { em todos os grupos, } \\
\text { para expressar as } \\
\text { funções comunicativas } \\
\text { interpessoais, exceto no } \\
\text { G2. Nas funções } \\
\text { comunicativas } & \text { não } \\
\text { interpessoais, } & \text { houve } \\
\text { diminuição } & \text { da } \\
\text { ocorrência do meio } \\
\text { comunicativo gestual, } \\
\text { aumento do meio } \\
\text { verbal, sem diferença } \\
\text { estatística entre os } \\
\text { grupos. Quanto ao meio } \\
\text { vocal, não houve } \\
\text { diferença ao longo do } \\
\text { tempo }\end{array}$ & $\begin{array}{l}\text { contribuíram para a } \\
\text { compreensão } \\
\text { processo do } \\
\text { comunicativo em } \\
\text { diferentes situações, } \\
\text { por meio da detecção } \\
\text { de diferenças em sua } \\
\text { percepção quanto à } \\
\text { funcionalidade da } \\
\text { comunicação de seus } \\
\text { filhos. }\end{array}$ \\
\hline
\end{tabular}

Fonte: Dados da pesquisa (2020).

É importante considerar que o transtorno de espectro autista possui manifestações significativas, como, gravidade da condição autista, nível do desenvolvimento, idade cronológica, por isso usa o termo espectro. Com relação a linguagem esta é importante em todos os aspectos da vida humana o desenvolvimento da oralidade, leitura e escrita são pontos relevantes na concepção da linguagem.

Monticelli (2015) sobre possibilidade do processo terapêutico fonoaudiólogo para a aquisição de linguagem, apresenta em sua tese o Brincar como forma utilizada para incentivar o ambiente terapêtico, todavia deve-se considerar as peculiaridades da criança com autismo, sendo o objetivo, proporcionar experiências interacionais e comunicativas significativas.

Ainda, em sua pesquisa, Monticelli (2015) utiliza as atividades lúdicas, em seu atendimento terapêutico intervenções que visam, a interação simbólica das crianças, como exemplo: o faz-de-conta, brincadeiras com fantoches, quebra cabeça, sendo possível observar o desenvolvimento da linguagem no brincar, pois eles atribuem funções aos brinquedos, além de uma funcionalidade ao jogo, tornando-o mais elaborado, resignificando as atividades do cotidiano em contextos sociais, o brincar em grupo, contribuindo ainda para o desenvolvimento da interação comunicativa que foram alcançados.

Neste viés, a pesquisa realizada mostra resultado positivo, as intervenções realizadas pelo fonoaudiólogo, que revelaram um processo evolutivo das crianças com TEA, referente ao desenvolvimento simbólico, aquisição da linguagem, brincadeira além de outras observações, como atenção compartilhada, interação durante as brincadeiras e comunicação não verbal e verbal.

Tamanaha, Chiari e Perissiinoto (2015), em sua pesquisa avaliaram a eficácia da intervenção terapêutica fonoaudiologica em crianças com TEA, a metodologia utilizada foram dois grupos, os que recebiam intervenção direta e indireta (GT) e apenas os que recebiam indireta (GO), empregando parte do teste ASIEP-2 ${ }^{1}$ : Autism Behavior Checklist, Avaliação de Interação e Amostra do Comportamento Vocal.

Observou-se que a intervenção terapêutica utilizada no grupo GT foi planejamento e execução com estratégias focadas nas habilidades e compreensão das inabilidades de cada criança, proposta pela fonoaudióloga, utilizou-se também

\footnotetext{
${ }^{1}$ Instrumento de Triagem de Autismo para Planejamento Educacional (ASIEP-2) O Instrumento de Triagem de Autismo para Planejamento Educacional, foi criado para facilitar o diagnóstico de autismo e monitorar o progresso educacional de indivíduos com autismo. Disponível em:
} 
assim como na pesquisa realizada por Monticelli (2015) o lúdico, além de estimulação física como cócegas. No grupo (GO) as intervenções foram realizadas pelos familiares e orientadas pela fonoaudióloga.

Tendo resultados significativos, os grupos tiveram desempenho, no grupo GT por exemplo, apresenta um padrão evolutivo bem mais acentuado que o grupo (GO), com relação a faixa de linguagem, o grupo (GT) também apresentou uma evolução mais perceptível que o (GO).

Considerando o exposto, analisa-se que a intervenção terapêutica fonoaudiológica direta e indireta depende possui eficácia na aquisição da linguagem, porém é importante considerar as observações que o fonoaudiólogo faz acerca das habilidades comunicativas e integrativas do autista, sendo ele é profissional que participar desse processo evolutivo, além de contribuir nas ações diretas e indiretas junto com a participação dos familiares.

Ishihara, Tamanaha e Perissinoto (2015) também fizeram pesquisa para verificar e comparar o desempenho indivíduos com TEA e o Transtorno Específico da Linguagem (TEL) o estudo mostrou que no TEA existem grandes prejuízos na identificação e interpretação de situações literais, pois possui comprometimentos linguísticos primários, as autores ressaltam que a dificuldade existente na interpretação das informações, são decorrentes das falhas primárias características da condição do TEA, como prejuízo no contato visual, na atenção compartilhada no reconhecimento na atribuição dos estados mentais .

Uma das grandes dificuldades de aquisição de linguagem, nos indivíduos autistas, está na sua dificuldade de interpretar, a melhoria de suas habilidades vai decorrer da sua condição de não falante para falante, ou seja, o autista dever possuir uma melhor compreensão do funcionamento linguístico, do que ele normalmente produz (repetição sem função, por exemplo).

Ishihara, Tamanaha e Perissinoto (2015) observaram em outro estudo realizado sobre o desempenho da linguagem, que existe um prejuízo pragmático em crianças com autismo, o desempenho intelectual do TEA tem influenciado e impactado nos aspectos cognitivos do processo de aquisição e desenvolvimento, sendo assim importante uma avaliação e a intervenção fonoaudiológica para melhoria do entendimento das capacidades linguísticas e cognitivas do TEA.

Nascimento; Ferreira e Braun (2016) em seus estudos apresentam em pesquisa realizada com considerações relevantes sobre a promoção da aprendizagem, em indivíduos com Transtorno do Espectro Autista , apresentando o mapeamento acerca do processo de escolarização chegando à conclusão o que tange a organização e aplicação de estratégias ou recursos em sala de aula ainda são pobres, considerando o recorte temporal utilizado na pesquisa mesmo com a aprovação de diversas normas legais sobre a inclusão escolar especificamente sobre TEA, percebe-se que existem poucos estudos pertinentes, sobre as práticas pedagógicas utilizadas e estratégias de ensino Linguagem e comunicação, estudos que abordam sobre análise e o uso da comunicação alternativa e ampliada do ensino.

Perotti (2016) em sua pesquisa fala que as metodologias aplicadas ao processo de aquisição de linguagem na escola, devem ser trabalhadas conforme as particularidades específicas da linguagem oral e da linguagem escrita, sendo que essas exigem tarefas tecnicamente distintas, o autor ainda coloca que as habilidades físicas são essenciais para a aquisição da linguagem.

Ainda, segundo o autor supracitado o autista no processo de alfabetização precisa que seja levado em consideração as escolhas do método empregado no processo de aprendizagem e as condições da sua severidade do autista, ou seja é preciso ter em vista o caráter subjetivo particular e singular de cada indivíduo do TEA. A atuação dos profissionais especializados no tratamento terapêutico de crianças TEA pode ser realizada com fonoaudiólogos e outros profissionais conforme as ações multidisciplinares que possibilitem uma mediação no processo de aquisição de linguagem

Marinho, Silva e Oliveira (2017) consideram que o autista, quando recusa a ordem linguística passa a construir uma série de impasse para sua constituição psíquica como sujeito, assim é necessárias ferramentas terapêuticas para contribuir na 
aquisição da linguagem. Seu estudo apresentou a musicalidade. As autoras afirmam que a utilização de instrumentos musicais nos momentos de brincadeira, são estratégias importantes do atendimento fonoaudiologico para crianças autistas.

Entre as intervenções apresentadas, conforme já mencionado, observa-se que as intervenções são formadas por um conjunto entre profissional e outros espaços como escola e família, assim percebe-se a importância de um planejamento, para que a aquisição de linguagem ocorra tanto do profissional no intuito de conhecer o sujeito como suas particularidades, como do planejamento a ser feito de acordo com a demanda que este recebe considerando que cada autista é um e que suas intervenções serão baseadas em suas necessidades e habilidades

Rabelo e Labigalini (2017) falam do trabalho multidisciplinar para autista, para um desenvolvimento global e eficaz, enquanto o trabalho do fonoaudiólogo será de promover a comunicação dos autistas independente de suas limitações e habilidades.

Marques (2018) fala que a consciência fonológica está diretamente ligada as habilidades de leitura e escrita, a capacidade de ler e escrever fluentemente. Revela que as intervenções são baseadas na consciência fonológica, estas são favoráveis para desenvolver as estas habilidades nos autistas, considerando que devem ser respeitadas a metodologia, tempo, número de informantes entre outros aspectos.

O programa utilizado por Marcos (2018) foi para avaliar crianças com autismo, na aquisição da linguagem, constatou em seu estudo que as crianças obtiveram avanços importantes, treinamento com melhores índices de pontuação e leitura, consciência fonológica comportamento verbal e motivação.

Já Bacelar e Nascimento (2018) em seu estudo, descrevem que as crianças acometidas pelo transtorno do espectro do autismo, possuem limitações e que essas estão presentes em sala de aula e que a comunicação pode ser realizada de várias formas mesmo que essas crianças, apresentam dificuldade na organização, fala incompreensível ou compreensível, pois muitas vezes a sua comunicação é bastante limitada, contudo é importante salientar que ela utilizar outros aspectos para que se realize a comunicação.

Os autores ainda completam a fala quando utilizam a mesmas estratégias que Monticelli (2015) e Tamanaha, Chiari e Perissiinoto (2015) com relação a atividades lúdicas, realizaram a intervenção, buscando os pontos em que cada criança, desperta seu interesse, uso de jogos pedagógicos, materiais concretos, atividades que utilizem imagem, vídeo, músicas ou seja, todas atividades que possam ampliar o desenvolvimento da criança autista.

Balestro e Fernandes (2019) apresentaram em seu estudo a avaliação do perfil profissional da comunicação das crianças com TEA, o PFC check-list utilizado pelos fonoaudiólogos para avaliar as frequências de ocorrência de cada comunicação como cada função comunicativa e sua forma de expressão.

Na pesquisa realizada por Balestro e Fernandes (2019) foi possível identificar o aumento nas ocorrências dos meios comunicativos principalmente nas comunicações interpessoal, considerando três intervenções propostas, o estudo apresenta um aumento significativo na aquisição da linguagem dos sujeitos, haja visto, que utilizaram métodos e programas com orientações de profissionais qualificados.

Foi possível observar que as atividades práticas de comunicação vão além de programas de orientação em grupo, as crianças também recebiam terapia fonoaudiológica individual, cada grupo recebeu intervenções diferenciadas, porém o atendimento fonoaudiológico, foram considerando o perfil de comunicação funcional Check-list PFC utilizando três momentos marcos 0, 5, 8 meses. Como resultado positivo para a aquisição de linguagem dos sujeitos pesquisados.

\section{Considerações Finais}

A Fonoaudiologia ocupa-se na habilitação e comunicação humana, provocando no autismo melhorias nas habilidades 
comunicativas e práticas pedagógicas que contribuirão para a promoção da aprendizagem e mapeamento das estratégias de ensino para os alunos com TEA.

Para a aquisição da linguagem dos indivíduos com TEA é necessário um trabalho multidisciplinar, desenvolver suas habilidades linguísticas de forma ampla, visando alcançar a manifestação da fala e escrita, com capacidade de expressar conceitos e reconhecer significados, assim alcançar um desenvolvimento global e amplo. A fonoaudiologia vem sendo eficaz no tratamento dessas alterações, utilizando intervenções e técnicas que consideram a singularidade dos indivíduos com transtorno de Espectro autista. É importante salientar que a aquisição da consciência fonológica deve haver a contribuição para a aprendizagem inicial da escrita, sendo importante o estímulo desta habilidade antes do ciclo de alfabetização, o que pode favorecer este processo e sinalizar precocemente, eventuais problemas de aprendizagem.

Portanto, considera-se alcançado o objetivo da pesquisa, haja vista que os artigos e teses apresentadas contribuem para apresentar pontuações relevantes sobre o processo de aquisição de linguagem no autismo. Todavia, salienta-se a necessidade de mais pesquisas sobre a temática, considerando que os artigos encontrados, relacionam outros aspectos na pesquisa, como escola e família.

\section{Referências}

American Psychiatric Association (2014). Manual Diagnóstico e Estatístico de Transtornos Mentais. (5a ed.). Editora Artmed.

Assumpção, JR., F. B. (2003). Transtornos abrangentes do desenvolvimento. In: Assumpção JR., F. B.; Kuczynski, E. (Org.), Tratado de Psiquiatria da Infância e Adolescência. (pp. 265-280). Atheneu

Assumpção, JR., F. B., \& Kuczynski, E. (2018). Autismo: conceito e diagnóstico. In: Ana Carolina Sella, Daniela Mendonça Ribeiro (Organizadoras). Análise do comportamento aplicada ao transtorno do espectro autista. (p. 321). Curitiba: Appris.

BigochinskI, E., \& Eckstein, M.P.W. (2016). A importância do trabalho com a consciência fonológica para a aprendizagem da leitura e da escrita. Ensaios pedagógicos, Revista Eletrônica do Curso de Pedagogia das Faculdades OPET, 11, 44-67. http://www.opet.com.br/faculdade/revistapedagogia/pdf/n11/artigo4.pdf.

Conselho Federal de Fonoaudiologia. Resolução $n^{o} \quad 309 \quad$ de $\quad 1^{\circ}$ de $\quad$ abril https://www.fonoaudiologia.org.br/resolucoes/resolucoes_html/CFFa_N_309_05.htm.

Rosal, A. G. C., Cordeiro, A. A. A., Silva, A. C. F., Silva, R. L., \& Queiroga, B. A. M. (2016). Contribuições da consciência fonológica e nomeação seriada rápida para a aprendizagem inicial da escrita. Revista CEFAC, 18(1), 74-85.

Fernandes, D. M. Z. (2016). A percepção de professores de educação infantil sobre a atuação fonoaudiológica na escola. (Dissertação de Mestrado). Universidade Estadual de Campinas, Faculdade de Ciências Médicas, Campinas, SP, Brasil. http://www.repositorio.unicamp.br/handle/REPOSIP/309753.

Ferraro, L. I. G. (2015). Perfil Funcional da Comunicação e Desempenho Sócio Cognitivo em Crianças com Diferentes apresentações de Autismo. (Dissertação de Mestrado). Escola Bahiana de Medicina e Saúde Pública, Salvador, BA, Brasil.

Firmino, A., (2017). Para uma melhor qualidade de vida: Terapias de diferentes áreas que favorecem o desenvolvimento do autista. Segredos da Mente. Alto Astral.

Freire, T. (2018) Ações da fonoaudiologia na escola: programa de estimulação da consciência fonológica em escolares do 1 ano, (Tese de Doutorado) Universalidade de São Paulo. Faculdade de Odontologia de Bauro. Bauro, SP, Brasil.

Donicht, G., Ceron, M. I. \& Keske-Soares, M. (2019). Erros ortográficos e habilidades de consciência fonológica em crianças com desenvolvimento fonológico típico e atípico. CoDAS, 31(1), e20170212. Epub February 11, 2019.https://dx.doi.org/10.1590/2317-1782/20182018212.

Instituto Neurosaber. (2020). A atuação do Fonoaudiólogo no processo de aprendizagem. https://institutoneurosaber.com.br/atuacao-fonoaudiologo-noprocesso-de-aprendizagem.

Ishihara, M. K., Tamanaha, A. C., \& Perissinoto, J. (2016). Compreensão de ambiguidade em crianças com Transtorno Específico de Linguagem e Fala e Transtorno do Espectro Autista. CoDAS, 28(6), 753-757. https://dx.doi.org/10.1590/2317-1782/20162015260.

Leite, K. K. A., Bittencourt, Zélia, Z. L. C., \& Silva, I. R. (2015). Fatores socioculturais envolvidos no processo de aquisição da linguagem escrita. Revista CEFAC, 17(2), 492-501. https://doi.org/10.1590/1982-021620153414.

Oliveira, E., Guaresi, R., \& Viali, L. (2019). Análise de preditores linguísticos e cognitivos da aquisição e aprendizado inicial da leitura e escrita. Revista VirtualLingu@Nostr@,6(1),3 -30.https://www.linguanostra.net/index.php/Linguanostra/article/view/125.

Paiva júnior, F. (2020). O que é autismo? Revista Autismo. 9, 8. 
Research, Society and Development, v. 10, n. 1, e15010111584, 2021

(CC BY 4.0) | ISSN 2525-3409 | DOI: http://dx.doi.org/10.33448/rsd-v10i1.11584

Rodrigues, J. M. C. Spencer, E. (2015). A Criança Autista: um estudo psicopedagógico. (2 a. ed.). Wak Editora.

Sampaio, C.M. Oliveira, G. F. (2017). O Desafio da Leitura e da Escrita em Crianças com Perturbação do Espectro do Autismo. Revista Multidisciplinar e de Psicologia, 11(36), 343-362.

Sanabe Júnior, Gilberto, G., Ana Cristina, S., Ana Paula, B., Ana Paula, M., Giselle, B., Kyrlian, B. \& Farinha, S. (2016). Visão dos graduandos do curso de Fonoaudiologia acerca da Fonoaudiologia Educacional a partir de suas experiências teórico-práticas. Revista CEFAC, 18(1), 198-208. https://doi.org/10.1590/1982-021620161816715.

Teixeira, G. (2016). Manual do Autismo. Best Seller. 